\title{
Prevalence of Sexually Transmitted Pathogen Coinfections in High Risk-Human Papillomaviruses Infected Women in Busan
}

\author{
Sun Hee Choi ${ }^{1, *}$, Hyunwoo Jin ${ }^{2, * *}$ and Kyung Eun Lee ${ }^{2, ;, * *}$ \\ ${ }^{I}$ Department of Laboratory Medicine, i-Angel Women's Clinic, Busan 46023, Korea \\ ${ }^{2}$ Department of Clinical Laboratory Science, College of Health Sciences, \\ Catholic University of Pusan, Busan 46252, Korea
}

\begin{abstract}
High risk-human papillomavirus (HR-HPV) is known to be a major cause of cervical cancer, and coinfection of sexually transmitted pathogen (STP) has been reported to cause persistent HPV infection. However, the relationship between HPV and STP coinfection remains unclear. The purpose of this study was to analyze the coinfection rate with STP in high-risk human papillomavirus infected women in Busan and to collect basic data for the prevention of cervical lesions. This study was carried out in 355 women who had concurrent HPV and STP screening at Busan local hospital between January 2016 and December 2017. HPV and STP coinfection was found in 187 (52.7\%) out of 355 cases. HR-HPV and STP coinfection was $82.9 \%$ higher than LR-HPV and STP coinfections 17.1\%. In HR-HPV infection, Ureaplasma species was the most common pathogen (47.1\%), followed by C. trachomatis (21.9\%) and Mycoplasma species (12.3\%). In the analysis of HR-HPV genotype according to STP, HPV 16 (12.0\%) was the most frequent, followed by HPV 58 (11.6\%), HPV 39 (11.1\%) and HPV 52 (10.2\%), but HPV 18 showed a low coinfection rate of $1.3 \%$. According to the results of age, HRHPV and STP coinfection rate was the highest at $41.9 \%$ among women aged 18 to 29. HR-HPV and Ureaplasma species showed the highest coinfection rates at all ages, followed by $C$. trachomatis and Mycoplasma species. Further studies with more samples will be needed to determine if the coinfection of HR-HPV and STPs is involved in the development of cervical tumors through histologic changes.
\end{abstract}

Key Words: High Risk-Human Papillomavirus (HR-HPV), Sexually Transmitted Pathogen (STP), Coinfection

\section{INTRODUCTION}

Human papillomavirus (HPV) types are classified as high risk groups or low risk groups based on their association with carcinogenic potential and cervical cancer. HPV-related carcinogenesis depends on different factors such as high risk-human papillomavirus (HR-HPV) infection, virus persistence, sustained viral oncogene expression, viral load and viral genome integration (zur Hausen, 2009). In addition to identifying HPV as the main etiological agent, additional risk factors such as use of oral contraceptives, smoking, early onset of sexual activity, multiple partners and chronic inflammation due to coinfection with other microorganisms, have been strongly associated with cervical lesion progression (Castellsagué et al., 2002). Recently, HPV and sexually transmitted pathogen (STP) coinfection have been reported as another cause of persistent HPV infection related to cer-

Received: October 30, 2019 / Revised: November 26, 2019 / Accepted: November 27, 2019

* Graduate student, ${ }^{* *}$ Professor.

†Corresponding author: Kyung Eun Lee. Department of Clinical Laboratory Science, College of Health Sciences, Catholic University of Pusan, Busan, 46252, Korea.

Tel: +82-51-510-0562, Fax: +82-51-510-0568, e-mail: kelee@cup.ac.kr

(C)The Korean Society for Biomedical Laboratory Sciences. All rights reserved.

(c) This is an Open Access article distributed under the terms of the Creative Commons Attribution Non-Commercial License (http://creativecommons.org/licenses/by-nc/3.0/) which permits unrestricted non-commercial use, distribution, and reproduction in any medium, provided the original work is properly cited. 
vical intraepithelial neoplasia. In particular, Chlamydia spp., Ureaplasma spp., Mycoplasma spp., and HPV coinfection have been reported to be associated with the development of cervical tumors (Bellaminutti et al., 2014; Camporiondo et al., 2016; Zhang et al., 2017; Kim et al., 2018). Although the mechanisms of HPV and STP coinfection in cervical carcinogenesis have not been elucidated yet, several studies have reported high rates of co-infection of HPV with $C$. trachomatis, M. hominis, and U. urealyticum (Markowska et al., 2002; Camporiondo et al., 2016; Liu et al., 2016). Therefore, it is time to continuously observe how HPV and STP coinfection causes changes in cervical epithelium.

Sex-mediated infection is highly prevalent in sexually active women and is presumed to be associated with HPV infection, as it targets ciliated epithelial cells or transitional epithelial cells. It is known that high rates of STPs in women with HPV infection are due to HPV-related factors such as changes in the immune system of the host or promotion of STPs due to inflammatory reactions (Liu et al., 2016; Zhang et al., 2017). Other studies, STPs have been reported as a modulator of continued development of HR-HPV infection (Silins et al., 2005; Samoff et al., 2005). However, the pathogenesis of HPV and STP coinfection in cervical neoplasia has not been elucidated, there is a lack of research data on HPV and STP coinfection in Korea. Recently the incidence of STPs infection and the prevalence of HR-HPV are increasing at the same time, so early detection and prevention of HR-HPV and STP coinfection may be a way to lower the incidence of cervical neoplasia. Therefore, the purpose of this study was to analyze the coinfection rate with STP in high-risk human papillomavirus infected women in Busan and to collect basic data for the prevention of cervical lesions.

\section{MATERIALS AND METHODS}

\section{Study population}

This study was performed from January 2016 to December 2017. The results of HPV and STP tests which were performed simultaneously, on 355 women who visited the local hospital in Busan, were analyzed. The age of the 355 women ranged from 18 to 85 years. Ethical approval was obtained from the Institutional Ethics Committee of the Catholic
University of Pusan (CUPIRB 2018-01-004). Cervical samples were collected using a cervical swab in $2 \mathrm{~mL}$ of phosphate buffered saline (PBS) (Noble Bio, Hwaseoug, South Korea) for detection of HPV and STPs.

\section{Genomic DNA extraction}

Genomic DNA extraction was performed from the cervical swab samples by using the QIAamp DNA kit (QIAGEN Inc., Chatsworth, CA, USA) according to the manufacturer's instructions. In brief, $20 \mu \mathrm{L}$ of proteinase $\mathrm{K}$ solution was added to each $1.5 \mathrm{~mL}$ tube. And then, $200 \mu \mathrm{L}$ of sample and $200 \mu \mathrm{L}$ of AL buffer were added to each tube and briefly vortexed. Each tube was then incubated at $56^{\circ} \mathrm{C}$ for $10 \mathrm{~min}$. These were quickly spun down and $200 \mu \mathrm{L}$ of EtOH was added and briefly vortexed. Again, they were briefly spun down, and total lysate was transferred to a QIAamp MinElute column (Qiagen) and centrifuged at 6,000 $\times \mathrm{g}$ for $1 \mathrm{~min}$. Flow through was removed, and $500 \mu \mathrm{L}$ of AW1 buffer was added and centrifuged at $6,000 \times \mathrm{g}$ for $1 \mathrm{~min}$. After being centrifuged, the flow through was removed and $500 \mu \mathrm{L}$ of AW2 buffer was added. Then, the samples were centrifuged at $6,000 \times \mathrm{g}$ for $1 \mathrm{~min}$. To dry the column membrane completely, the columns were centrifuged at $20,000 \times$ g. Each column was then transferred to a new tube, and finally, $30 \mu \mathrm{L}$ of AE buffer was added to extract gDNA. The columns were incubated at room temperature for $1 \mathrm{~min}$ and then centrifuged at $6,000 \times \mathrm{g}$ for $1 \mathrm{~min}$.

\section{Detection of Human papillomavirus genotypes}

HPV genotyping was performed by the Omniplex-HPV test (GeneMatrix Inc., Seongnam, Korea) that simultaneously analyzes $40 \mathrm{HPV}$ genotypes (15 HR-HPV types including HPV 16, 18, 31, 33, 35, 39, 45, 51, 52, 56, 58, 59, 68, 73, 82 and 4 probable HR-HPV types including HPV 26, 53, 66 and 69 as well as $21 \mathrm{LR}-\mathrm{HPV}$ types including HPV 6, 11, 30, 32, 40, 42, 43, 44, 54, 55, 61, 62, 67, 70, 71, 72, 74, 81, 83,84 and 87) using the liquid bead microarray (LBMA) method and polymerase chain reaction (PCR) followed by Luminex MAP $^{\circledR}$ technology in HPV DNA extracted from cervical swab samples. Omniplex-HPV testing (GeneMatrix Inc.) was performed according to the manufacturer's instructions. Briefly, Omniplex-HPV uses HPV-specific oligo- 
nucleotides for multiplex PCR with a sample quality control targeting the $\beta$-globin gene. HPV L1 genes were amplified by using a single-closed tube nested-PCR. Two denaturation steps $\left(2 \mathrm{~min}\right.$ at $50^{\circ} \mathrm{C}$ and $15 \mathrm{~min}$ at $95^{\circ} \mathrm{C}$ ) are followed by 60 cycles of an amplification step; 10 cycles of a preamplification step $\left(30 \mathrm{sec}\right.$ for denaturation at $95^{\circ} \mathrm{C}, 30 \mathrm{sec}$ for annealing at $55^{\circ} \mathrm{C}, 60 \mathrm{sec}$ for elongation at $72^{\circ} \mathrm{C}$ ) and 50 cycles of the amplification step ( $30 \mathrm{sec}$ for denaturation at $95^{\circ} \mathrm{C}, 60 \mathrm{sec}$ for annealing at $40^{\circ} \mathrm{C}, 30 \mathrm{sec}$ for elongation at $72^{\circ} \mathrm{C}$ ) as well as a final elongation step of $10 \mathrm{~min}$ at $72^{\circ} \mathrm{C}$. Hybridization of amplified PCR products and beads immobilized with probes specific for each of the 40 HPV genotypes was then performed. A polystyrene magnetic bead with a diameter of 6.5 micrometers was internally dyed with various ratios of two spectrally distinct fluorophores to detect various kinds types of genotypes. After hybridization, beads are individually identified using a specialized device within the MAGPIX ${ }^{\circledR}$ system (Luminex Corp., Austin, TX, USA). If the value of MFI (Mean Fluorescence Intensity) is 100 or more, test results are judged to be positive.

\section{Detection of sexually transmitted pathogens}

The uterine cervical specimens were examined by using the ISD STD 12 AES TYPING KIT (DIOGENE Co. Seongnam, South Korea) that identify the 12 species of causative organism including (T. pallidum, M. genitalium, Neisseria gonorrhoeae, U. pavum, M. hominis, U. urealyticum, Gardenerella vaginalis, C. trachomatis, Trichomonas vaginalis, HSV I, HSV II, and Candida albicans). Cell collection for gDNA extraction requires taking $0.5 \mathrm{~mL}$ of specimen and transferring it to a $1.5 \mathrm{~mL}$ tube and centrifuging at $1,000 \times \mathrm{g}$ for $5 \mathrm{~min}$. For gDNA extraction, the supernatant is removed completely. $150 \mu \mathrm{L}$ was added to loosen the cell pellet and samples were boiled for 10 mins at $105^{\circ} \mathrm{C}$ on a heat block. After incubation at room temperature, the samples were centrifuged at $12,500 \times \mathrm{g}$ for $5 \mathrm{~min}$. The supernatants were transferred to a new $1.5 \mathrm{~mL}$ tube. After PCR reaction, the PCR products were electrophoresed to identify the target specific bands. At this time, when at least one expression occurs in each band, regardless of the STD type, whether positive or negative, the value of the internal control test should be at least $2.0 \mathrm{ng} / \mathrm{mL}$.

\section{RESULTS}

\section{Prevalence of coinfection with HPV and STPs}

Among 355 cases, HPV and STP coinfection constituted 187 cases $(52.7 \%)$, which was higher than the 167 cases (47.3\%) that were STP negative while being positive for HPV. HPV and STP coinfections were higher in the HR-HPV group $(155 / 187,82.9 \%)$ than in the LR-HPV group (32/187, $17.1 \%)$. According to frequency, coinfection of HR-HPV and STPs occurred in the following order: Ureaplasma spp. (73/155, 47.1\%), C. trachomatis (34/155, 21.9\%), Mycoplasma spp. (19/155, 12.3\%), G. vaginalis (17/155, 11.0\%), HSV II (5/155, 3.2\%), T. vaginalis (3/155, 1.9\%), N. gonorrhoeae $(2 / 155,1.3 \%)$ and Candida albicans $(2 / 155,1.3 \%)$

Table 1. Prevalence of coinfection with HPV and STP

\begin{tabular}{|c|c|c|c|}
\hline Coinfections & $\begin{array}{c}\text { Total } \\
\mathrm{N}=355 \\
(\%)\end{array}$ & $\begin{array}{c}\text { HR-HPV } \\
\mathrm{N}=155 \\
(\%)\end{array}$ & $\begin{array}{c}\text { LR-HPV } \\
\mathrm{N}=32 \\
(\%)\end{array}$ \\
\hline HPV (+) / STP $\left(^{-}\right)$ & $\begin{array}{c}168 \\
(47.3)\end{array}$ & - & - \\
\hline HPV (+) / STP (+) & $\begin{array}{c}187 \\
(52.7)\end{array}$ & & \\
\hline Chlamydia trachomatis & & $\begin{array}{c}34 \\
(21.9)\end{array}$ & $\begin{array}{c}3 \\
(9.4)\end{array}$ \\
\hline Ureaplasma urealyticum & & $\begin{array}{c}60 \\
(38.7)\end{array}$ & $\begin{array}{c}8 \\
(25.0)\end{array}$ \\
\hline Ureaplasma pavum & & $\begin{array}{c}13 \\
(8.4)\end{array}$ & $\begin{array}{c}6 \\
(18.8)\end{array}$ \\
\hline Mycoplasma genitalium & & $\begin{array}{c}9 \\
(5.8)\end{array}$ & - \\
\hline Mycoplasma hominis & & $\begin{array}{c}10 \\
(6.5)\end{array}$ & $\begin{array}{c}4 \\
(12.5)\end{array}$ \\
\hline Gardenerella vaginalis & & $\begin{array}{c}17 \\
(11.0)\end{array}$ & $\begin{array}{c}8 \\
(25.0)\end{array}$ \\
\hline Neisseria gonorrhoeae & & $\begin{array}{c}2 \\
(1.3)\end{array}$ & - \\
\hline Treponema pallidum & & - & - \\
\hline Trichonomas vaginalis & & $\begin{array}{c}3 \\
(1.9)\end{array}$ & - \\
\hline Herpes simplex virus I & & - & $\begin{array}{c}1 \\
(3.1)\end{array}$ \\
\hline Herpes simplex virus II & & $\begin{array}{c}5 \\
(3.2)\end{array}$ & $\begin{array}{c}1 \\
(3.1)\end{array}$ \\
\hline Candida albicans & & $\begin{array}{c}2 \\
(1.3)\end{array}$ & $\begin{array}{c}1 \\
(3.1)\end{array}$ \\
\hline
\end{tabular}


(Table 1).

\section{Coinfection rates with STPs according to HR-HPV genotypes}

HPV genotypes were analyzed for a total of 225 cases, including single and multiple infections. In the analysis of coinfection rates with STPs according to HR-HPV genotypes, HPV $16(27 / 225,12.0 \%)$ was the most frequent, followed by HPV 58 (26/225, 11.6\%), HPV 39 (25/225, 11.1\%), HPV 52 (23/225, 10.2\%), HPV 53 (22/225, 9.8\%) HPV 59 (18/225, 8.0\%), HPV 56 (16/225, 7.1\%), HPV 51 (15/225, 6.7\%), HPV 68 (14/225, 6.2\%), and HPV 66 (11/225, 4.9\%), but HPV 18 showed a low coinfection rate of $1.3 \%(3 / 225)$ (Table 2).

Among the 27 cases of HPV type 16 infection, 11 cases
(40.7\%) were co-infected with Ureaplasma spp., followed by 7 cases (25.9\%) with $C$. trachomatis, and 4 cases (14.8\%) with $G$ vaginalis coinfection. HPV 58, 39, 52 and 53 were the most common coinfection of Ureaplasma spp., followed by C. trachomatis and Mycoplasma species (Table 2, Fig. 1).

\section{Positive rate of HR-HPV and STPs coinfection by age} group

Comparing coinfection of HPV and STPs according to age, the rate was found to be the highest among those 18 to 29 years of age $(65 / 155,41.9 \%)$, followed by 30 to 39 years (49/155, 31.6\%), 40 to 49 years $(26 / 155,16.8 \%), 50$ to 59 years $(15 / 155,9.7 \%)$. So, coinfection rates of HPV and STP have decreased with age (Table 3). HR-HPV and Ureaplasma species showed the highest coinfection rates at all

Table 2. Prevalence of coinfection with STP according to HR-HPV genotypes

\begin{tabular}{|c|c|c|c|c|c|c|c|c|c|c|c|c|c|}
\hline \multirow{2}{*}{ Genotypes } & \multirow{2}{*}{$\begin{array}{l}\text { Coinfection } \\
\mathrm{N}(\%)\end{array}$} & \multicolumn{12}{|c|}{ STPs } \\
\hline & & CT & UU & UP & MG & $\mathrm{MH}$ & GV & NG & $\mathrm{TP}$ & $\mathrm{TV}$ & HSV I & HSV II & Candida \\
\hline HR-HPV 16 & $27(12.0)$ & 7 & 10 & 1 & - & 3 & 4 & 1 & - & - & - & 1 & - \\
\hline 18 & $3(1.3)$ & 1 & 1 & - & - & - & - & - & - & - & - & 1 & - \\
\hline 26 & - & - & - & - & - & - & - & - & - & - & - & - & - \\
\hline 31 & $5(2.2)$ & 1 & 4 & - & - & - & - & - & - & - & - & - & - \\
\hline 33 & $3(1.3)$ & 1 & 2 & - & - & - & - & - & - & - & - & - & - \\
\hline 35 & $5(2.2)$ & 2 & 2 & - & - & - & 1 & - & - & - & - & - & - \\
\hline 39 & $25(11.1)$ & 9 & 9 & 1 & 1 & 2 & 2 & - & - & 1 & - & - & - \\
\hline 45 & $2(0.9)$ & 1 & 1 & - & - & - & - & - & - & - & - & - & - \\
\hline 51 & $15(6.7)$ & 6 & 5 & 1 & 1 & 1 & 1 & - & - & - & - & - & - \\
\hline 52 & $23(10.2)$ & 6 & 8 & 3 & 1 & 2 & 2 & - & - & - & - & 1 & - \\
\hline 53 & $22(9.8)$ & 4 & 7 & 2 & 3 & 2 & 2 & - & - & 1 & - & - & 1 \\
\hline 56 & $16(7.1)$ & 3 & 6 & - & 1 & 3 & 1 & 1 & - & 1 & - & - & - \\
\hline 58 & $26(11.6)$ & 5 & 12 & 3 & 4 & - & 2 & - & - & - & - & - & - \\
\hline 59 & $18(8.0)$ & 3 & 4 & 2 & 2 & 1 & 3 & - & - & 1 & - & 1 & 1 \\
\hline 66 & $11(4.9)$ & 2 & 4 & 1 & 1 & 1 & 1 & - & - & - & - & - & 1 \\
\hline 68 & $14(6.2)$ & 1 & 2 & 2 & 1 & 2 & 3 & 1 & - & 1 & - & 1 & - \\
\hline 69 & - & - & - & - & - & - & - & - & - & - & - & - & - \\
\hline 70 & $9(4.0)$ & - & 9 & - & - & - & - & - & - & - & - & - & - \\
\hline 73 & - & - & - & - & - & - & - & - & - & - & - & - & - \\
\hline 82 & $1(0.4)$ & - & - & 1 & - & - & - & - & - & - & - & - & - \\
\hline Total & $225(100)$ & 52 & 86 & 17 & 15 & 17 & 22 & 3 & 0 & 5 & 0 & 5 & 3 \\
\hline
\end{tabular}

CT: Chlamydia trachomatis, UU: Ureaplasma urealyticum, UP: Ureaplama pavum, MG: Mycoplasma genitalium, MH: Mycoplasma hominis, GV: Gardenerella vaginalis, NG; Neisseria gonorrhoeae, TP: Treponema pallidum, TV: Trichonomas vaginalis, HSV I: Herpes simplex virus I, HSV II: Herpes simplex virus II, Candida: Candida albicans, STP: Sexually transmitted pathogen 


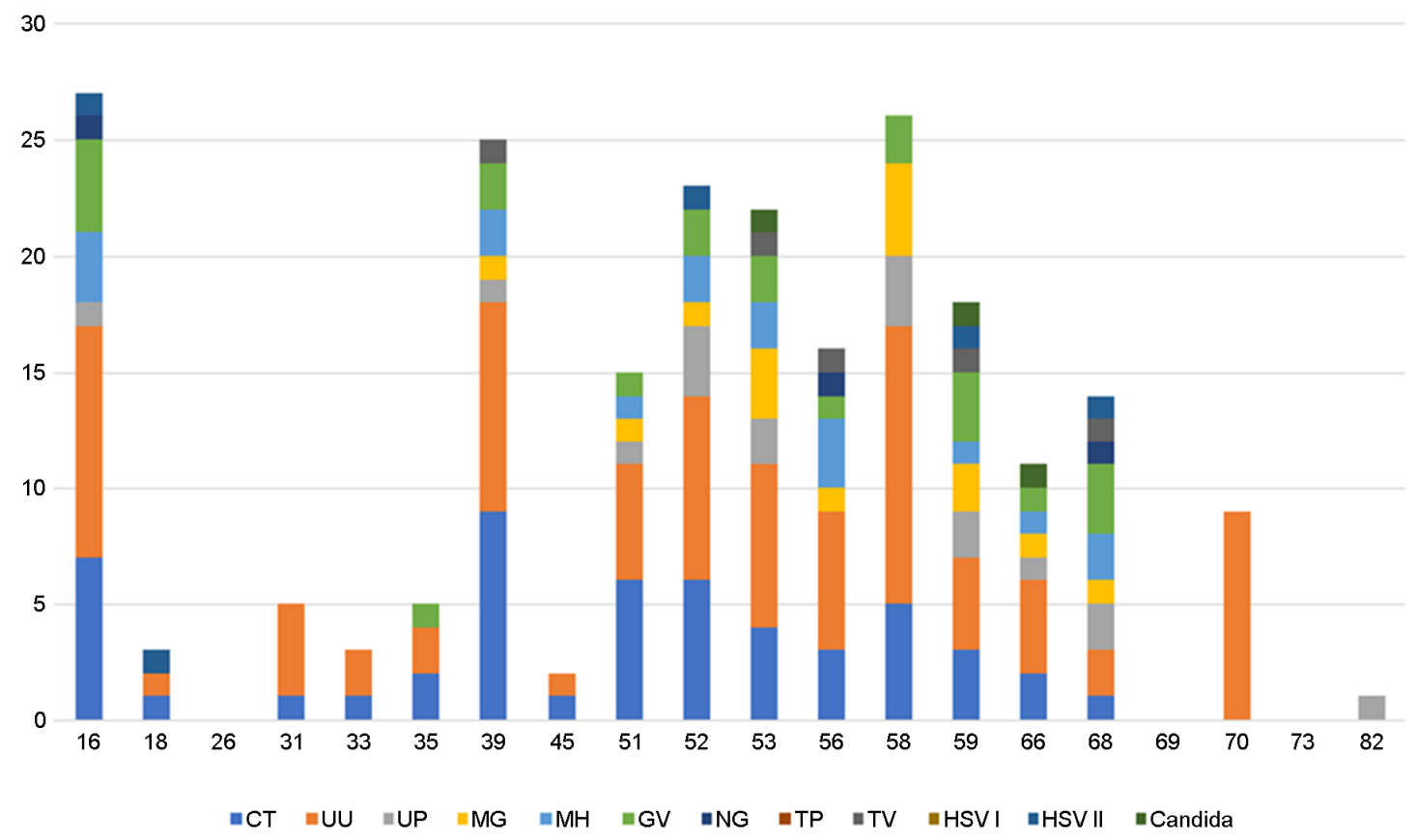

Fig. 1. Distribution of STPs according to HR-HPV genotypes; Among the 27 cases of HPV type 16 infection, 11 cases (40.7\%) were coinfected with Ureaplasma spp., followed by 7 cases (25.9\%) with C. trachomatis, and 4 cases (14.8\%) with G. vaginalis coinfection. HPV 58, 39, 52 and 53 were the most common coinfection of Ureaplasma spp., followed by C. trachomatis and Mycoplasma spp.

Table 3. Positive rate of HR-HPV and STP coinfection by age group

\begin{tabular}{|c|c|c|c|c|c|}
\hline \multirow[b]{2}{*}{ STP } & \multirow{2}{*}{$\begin{array}{c}\text { Total } \\
\mathrm{N}=155\end{array}$} & \multicolumn{4}{|c|}{ HR-HPV } \\
\hline & & $\begin{array}{c}18 \sim 29 y \\
N=65\end{array}$ & $\begin{array}{c}30 \sim 39 y \\
N=49\end{array}$ & $\begin{array}{c}40 \sim 49 y \\
N=26\end{array}$ & $\begin{array}{c}50 \sim 59 \mathrm{y} \\
\mathrm{N}=15\end{array}$ \\
\hline $\mathrm{CT}$ & 34 & 16 & 13 & 2 & 3 \\
\hline UU & 60 & 20 & 23 & 12 & 5 \\
\hline UP & 13 & 5 & 2 & 5 & 1 \\
\hline MG & 9 & 4 & 4 & 1 & - \\
\hline MH & 10 & 5 & 2 & - & 3 \\
\hline GV & 17 & 8 & 3 & 4 & 2 \\
\hline NG & 2 & 1 & - & - & 1 \\
\hline TP & 0 & - & - & - & - \\
\hline TV & 3 & 1 & 1 & 1 & - \\
\hline HSV I & 0 & - & - & - & - \\
\hline HSV II & 5 & 3 & 1 & 1 & - \\
\hline Candida & 2 & 2 & - & - & - \\
\hline
\end{tabular}

CT: Chlamydia trachomatis, UU: Ureaplasma urealyticum, UP: Ureaplasma pavum, MG: Mycoplasma genitalium, MH: Mycoplasma hominis, GV: Gardenerella vaginalis, NG; Neisseria gonorrhoeae, TP: Treponema pallidum, TV: Trichonomas vaginalis, HSV I: Herpes simplex virus 1, HSV II: Herpes simplex virus 2, Candida: Candida albicans ages, followed by C. trachomatis and Mycoplasma species (Fig. 2).

\section{DISCUSSION}

STPs are an important cause of morbidity among sexually active women. HPV infection is one of the most prevalent STPs among women aged under 35 years worldwide (Parthenis et al., 2018), and is a major cause of cervical cancer. The development of cervical lesions depends on infection by HR-HPV genotypes, such as HPV 16 and HPV 18. Persistent HR-HPV infection has been causally associated with cervical intraepithelial neoplasia/squamous intraepithelial lesions (CIN/SIL) and invasive cervical carcinomas (zur Hausen, 2002). Although these HR-HPV infections are naturally overcome by $90 \%$ of patients within 1 to 2 years, women with persistent infection have a 100 -fold greater chance of developing cervical dysplasia, a pre-cervical cancer stage, than normal women. HR-HPV overexpresses E6 and E7 viral oncogenes and inhibits tumor suppressor genes $\mathrm{p} 53$ and $\mathrm{pRb}$, causing transient proliferation of abnor- 


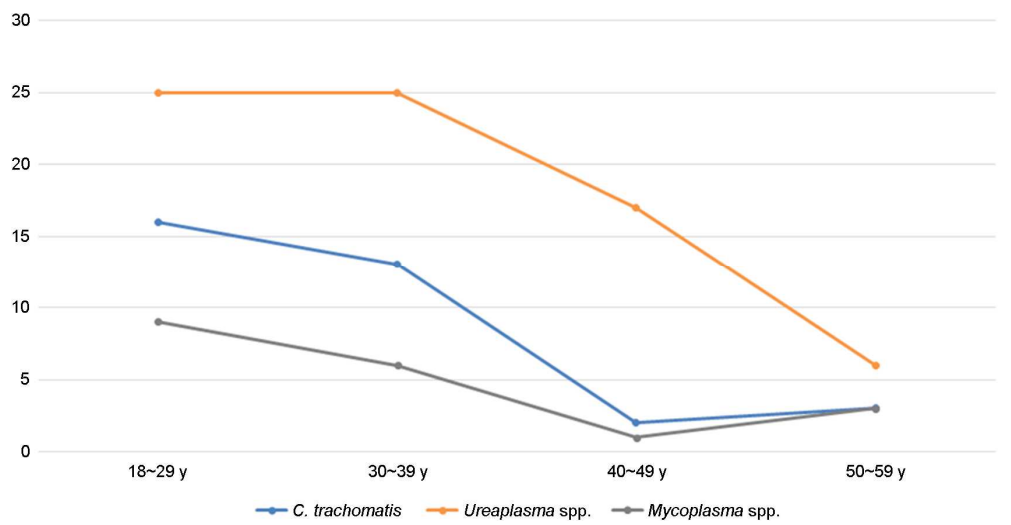

Fig. 2. Distribution of HR-HPV and Ureaplasma spp., C. trachomatis and Mycoplasma spp. Coinfection by age group; HR-HPV and STP coinfection rate was the highest at women aged 18 to 29. HR-HPV and Ureaplasma species showed the highest coinfection rates at all ages, followed by $C$. trachomatis and Mycoplasma species. mal cells, leading to cervical cancer (Scheffner et al., 1990; Werness et al., 1990).

Cervical carcinogenesis is not facilitated by HPV infection alone: It is also associated with environmental factors, such as, long-term use of oral contraceptives (Moreno et al., 2002), smoking (Plummer et al., 2003), human immunodeficiency virus (HIV) infection (Ahdieh et al., 2001), and sexually trans mitted pathogens (STPs) other than HPV and HIV (Schmauz et al., 1989). STPs are a cause of serious diseases such as chronic PID, infertility and ectopic pregnancy, and has also been reported as a factor involved in the development of cervical cancer (Ljubin-Sternak and Mestrovic, 2014). STP infection may function as an entryway, allowing the access of HPV to the basal epithelium layer (Samoff et al., 2005; Paba et al., 2008; Paavonen, 2012). STP can induce chronic inflammation, cervical hypertrophy (Markowska et al., 1999; Markowska et al., 2002) and squamous metaplasia, as metaplastic cells are a potential target for the HPV pathogen (Paavonen et al., 2012). Continued infection with HRHPV by STP infection, especially Mycoplasma spp., $C$. trachomatis, and $U$. urealyticum increases the risk of cervical cell degeneration (Silins et al., 2005; Samoff et al., 2005).

Other studies have shown an increased incidence of Mycoplasma species, C. trachomatis, and U. urealyticum infection during HPV infection (Van Der Pol, 2014). In addition, it has been reported the STP infection rate is high in HR-HPV infection. In this study, the positive rate of STP was $52.7 \%$ and the negative rate was $47.3 \%$ when HPV positive. HPV and STP coinfections were higher in the HRHPV group (155/187, 82.9\%) than in the LR-HPV group (32/
187, 17.1\%). In HR-HPV infection, Ureaplasma spp. was the most common pathogen $(73 / 155,47.1 \%)$, followed by C. trachomatis $(34 / 155,21.9 \%)$ and Mycoplasma species (19/155, 12.3\%). Kim et al. (2016) reported that the incidence of HR-HPV was 1.47 times higher when positive for STP infection than negative. In a large study of 1,218 married women in China, $U$. urealyticum was the most frequently identified pathogen, present in $35.5 \%$ of the women examined (Zhang et al., 2017). In Mexico, the HPV and Ureaplasma species coinfection rate was $57.7 \%$ higher than other STPs (Magana-Contreras et al., 2015). Therefore, it is necessary to follow up the cervical epithelial changes due to HPV and STP coinfection including Ureaplasma species.

Recently, mortality from cervical cancer has declined significantly, but the rate of HPV infection in young women has increased sharply (Zhang et al., 2017). In this study, comparing coinfection of HPV and STPs according to age, the rate was found to be the highest among those 18 to 29 years of age $(65 / 155,41.9 \%)$, followed by 30 to 39 years $(49 / 155,31.6 \%), 40$ to 49 years $(26 / 155,16.8 \%), 50$ to 59 years $(15 / 155,9.7 \%)$. So, coinfection rates of HPV and STP have decreased with age. These results suggest that high HR-HPV and STP coinfection rates in young women may be a risk factor for chronic cervical disease. Ji (2017) reported that HPV and STP coinfection was associated with cervical neoplasia. Ekiel et al. (2009) reported that U. urealyticum is more common in women with HR-HPV infection and occurred more frequently in women with squamous intraepithelial lesions. In the future, it is necessary to observe continuously whether STP infection causes HR-HPV per- 
sistent infection and causes cervical lesions.

In conclusion, HR-HPV and STP coinfection was higher in young women aged 18 to 39 years. In particular, continuous monitoring is necessary to prevent the incidence of cervical cancer in patients with coinfection of HR-HPV and Ureaplasma spp., C. trachomatis, Mycoplasma species. Future studies with more specimens will be needed to find the exact association regarding HR-HPV and STP coinfection. In addition, an experiment to analyze the effect of cervical cancer on the development of cervical tumors should be added through a study that contrasts histologic results. Finally, reducing women's HPV and STP infection rates is a shortcut to reduce the incidence of cervical neoplasia.

\section{ACKNOWLEDGEMENT}

This paper was supported by Brain Busan 21 plus project.

\section{CONFLICT OF INTEREST}

The authors declare no conflicts of interest.

\section{REFERENCES}

Ahdieh L, Klein RS, Burk R, Cu-Uvin S, Schuman P, Duerr A, Safaeian M, Astemborski J, Daniel R, Shah K. Prevalence, incidence, and type specific persistence of human papillomavirus in human immunodeficiency virus (HIV)-positive and HIV negative women. J Infect Dis. 2001. 184: 682-690.

Bellaminutti S, Seraceni S, De Seta F, Gheit T, Tommasino M, Comar M. HPV and Chlamydia trachomatis co-detection in young asymptomatic women from high incidence area for cervical cancer. J Med Virol. 2014. 86: 1920-1925.

Camporiondo MP, Farchi F, Ciccozzi M, Denaro A, Gallone D, Maracchioni F, Favalli C, Ciotti M. Detection of HPV and co-infecting pathogens in healthy Italian women by multiplex real-time PCR. Infez Med. 2016. 24: 12-17.

Castellsagué X, Bosch FX, Muñoz N. Environmental co-factors in HPV carcinogenesis. Virus Res. 2002. 89: 191-199.

Ekiel AM, Friedek DA, Romanik MK, JóźwiakJ, Martirosian G. Occurrence of Ureaplasma parvum and Ureaplasma urealyticum in women with cervical dysplasia in Katowice, Poland. J Korean Med Sci. 2009. 24: 1177-1181.

Ji YI. Co-infections with human papillomavirus and Mycoplasmal Ureaplasma spp. in women with abnormal cervical cytology.
Gynaecol Obstet. 2017. 1: 1-3.

Kim HS, Kim TJ, Lee IH, Hong SR. Associations between sexually transmitted infections, high-risk human papillomavirus infection, and abnormal cervical Pap smear results in $\mathrm{OB} /$ GYN outpatients. J Gynecol Oncol. 2016. 27: e49.

Kim SI, Yoon JH, Park DC, Lee DS, Lee SJ, Choe HS, Kim JH, Park TC, Lee SJ. Co-infection of Ureaplasma urealyticum and human papilloma virus in asymptomatic sexually active individuals. Int J Med Sci. 2018. 15: 915-920.

Liu J, Liu W, Liu Y, Zhou X, Zhang Z, Sun Z. Prevalence of microorganisms co-infections in human papillomaviruses infected women in Northern China. Arch Gynecol Obstet. 2016. 293: 595-602.

Ljubin-Sternak S, Mestrovic T. Chlamydia trachomatis and genital Mycoplasmas: pathogens with an impact on human reproductive health. J Pathog. 2014. 183167.

Magana-Contreras M, Contreras-Paredes A, Chavez-Blanco A, Lizzano M, De la Cruz-Hernandez Y, De la Cruz-Hernandez E. Prevalence of sexually transmitted pathogens associated with HPV infection in cervical samples in a Mexican population. J Med Virol. 2015. 87: 2098-2105.

Markowska J, Fischer N, Filas V, Fischer Z, Breborowicz J, Markowski M. The role of Chlamydia trachomatis infection in cervical cancer development. Eur J Gynaecol Oncol. 1999. 20: $144-146$.

Markowska J, Fischer N, Fischer Z, Warchol JB. Chlamydia trachomatis infection in women with CIN and invasive uterine cervix cancer. Significance of hormonal status. Eur J Gynaecol Oncol. 2002. 23: 511-513.

Moreno V, Bosch FX, Muñoz N, Meijer CJ, Shah KV, Walboomers JM, Herrero R, Franceschi S. Effect of oral contraceptives on risk of cervical cancer in women with human papillomavirus infection. The Lancet. 2002. 359: 1085-1092.

Paavonen J. Chlamydia trachomatis infections of the female genital tract: state of the art. Ann Med. 2012. 44: 18-28.

Paba P, Bonifacio D, Di Bonito L, Ombres D, Favalli C, Syrjanen K, Ciotti M. Co-expression of HSV2 and Chlamydia trachomatis in HPV-positive cervical cancer and cervical intraepithelial neoplasia lesions is associated with aberrations in key intracellular pathways. Intervirology. 2008. 51: 230-234.

Parthenis C, Panagopoulos P, Margari N, Kottaridi C, Spathis A, Pouliakis A, Konstantoudakis S, Chrelias G, Chrelias C, Papantoniou N, Panayiotides IG, Tsiodras S. The association between sexually transmitted infections, human papillomavirus, and cervical cytology abnormalities among women in Greece. 
International Journal of Disease. 2018. 73: 72-77.

Plummer M, Herrero R, Franceschi S, Meijer CJ, Snijders P, Bosch FX, de Sanjosé S, Muñoz N; IARC Multi-centre Cervical Cancer Study Group. Smoking and cervical cancer: pooled analysis of the IARC multi-centric case--control study. Cancer Causes Control. 2003. 14: 805-814.

Samoff E, Koumans EH, Markowitz LE, Sternberg M, Sawyer MK, Swan D, Papp JR, Black CM, Unger ER. Association of Chlamydia trachomatis with persistence of high-risk types of human papillomavirus in a cohort of female adolescents. Am J Epidemiol. 2005. 162: 668-675.

Scheffner M, Werness BA, Huibregtse JM, Levine AJ, Howley PM.

The E6 oncoprotein encoded by human papillomavirus types 16 and 18 promotes the degradation of p53. Cell. 1990. 63: 1129-1136.

Schmauz R, Okong P, de Villiers EM, Dennin R, Brade L, Lwanga SK, Owor R. Multiple infections in cases of cervical cancer from a high-incidence area in tropical Africa. Int J Cancer. 2989. 43: 805-809.

Silins I, Ryd W, Stre A, Wadell G, Tornberg S, Hansson BG. Chlamydia trachomatis infection and persistence of human papillomavirus. Int J Cancer. 2005. 16: 110-115.
Van Der Pol B. Sexually transmitted infections in women. Scand $\mathbf{J}$ Clin Lab Invest Suppl. 2014. 244: 68-74.

Werness BA, Levine AJ, Howley PM. Association of human papillomavirus types 16 and 18 E6 proteins with p53. Science. 1990. 248: 76-79.

Zhang D, Li T, Chen L, Zhang X, Zhao G, Liu Z. Epidemiological investigation of the relationship between common lower genital tract infections and high-risk human papillomavirus infections among women in Beijing. China. PloS One. 2017. 12: $\mathrm{e} 0178033$.

zur Hausen. H. Papillomaviruses and cancer: from basic studies to clinical application. Nat Rev Cancer. 2002. 2: 342-350.

zur Hausen H. Papillomaviruses in the causation of human cancers a brief historical account. Virology. 2009. 384: 260-265.

https://doi.org/10.15616/BSL.2019.25.4.390

Cite this article as: Choi SH, Jin H, Lee KE. Prevalence of Sexually Transmitted Pathogen Coinfections in High Risk-Human Papillomaviruses Infected Women in Busan. Biomedical Science Letters. 2019. 25: 390-397. 